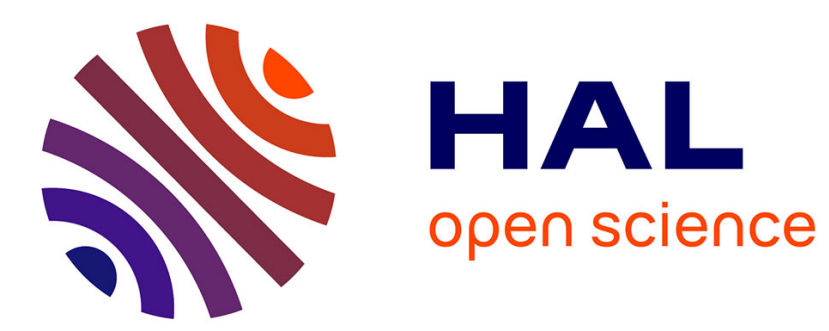

\title{
Laser-CVD 3D Rapid Prototyping of Laser Driven Moveable Micro-Objects
}

\author{
O. Lehmann, M. Stuke
}

\section{To cite this version:}

O. Lehmann, M. Stuke. Laser-CVD 3D Rapid Prototyping of Laser Driven Moveable Micro-Objects. Journal de Physique IV Proceedings, 1995, 05 (C5), pp.C5-601-C5-605. 10.1051/jphyscol:1995571 . jpa-00253933

\section{HAL Id: jpa-00253933 https://hal.science/jpa-00253933}

Submitted on 1 Jan 1995

HAL is a multi-disciplinary open access archive for the deposit and dissemination of scientific research documents, whether they are published or not. The documents may come from teaching and research institutions in France or abroad, or from public or private research centers.
L'archive ouverte pluridisciplinaire HAL, est destinée au dépôt et à la diffusion de documents scientifiques de niveau recherche, publiés ou non, émanant des établissements d'enseignement et de recherche français ou étrangers, des laboratoires publics ou privés. 


\title{
Laser-CVD 3D Rapid Prototyping of Laser Driven Moveable Micro-Objects
}

O. Lehmann and M. Stuke

Max-Planck-Institut für Biophysikalische Chemie, P.O. Box 2841, 37018 Göttingen, Germany

\begin{abstract}
Using continuous wave visible $(514 \mathrm{~nm}, 488 \mathrm{~nm}$ ) laser beams and the gaseous precurcsors trimethylamine alane $\left(\mathrm{CH}_{3}\right)_{3} \mathrm{NAlH}_{3}$ and oxygen, free-standing three-dimensional (3D) $\mathrm{Al}_{2} \mathrm{O}_{3}$ ceramic microstructures can be directly written under software control. By suitable laser irradiation, parts of these 3D microobjects can be moved through thermal expansion forces. This is a first step towards laser rapid prototyping of optically driven 3D microobjects such as microtweezers and microrobots. Examples will be presented.
\end{abstract}

\section{INTRODUCTION}

Microelectronics has made a tremendous development during the last decades, characterized by minimum feature sizes reduced by orders of magnitude. Suitable lithographic techniques combined with selective deposition and etching are an important factor for reliable and high output industrial production, especially in batch numbers. During the last years, some of these silicon based techniques have been modified and used to produce microstructures serving not only electronic, but mainly mechanical purposes. Because of the principally planar nature of those processes, complex vertical shape variations require a large number of timeconsuming steps. Photomask requirements also make such processes interesting mainly for large-scale applications.

However, first demonstrations of the usability of laser direct writing techniques for micromechanical applications that can produce fine structures in one single maskless step have been given.

Using a preformed substrate, three-dimensional metal microstructures can be generated [1].

Direct layer-by-layer direct write techniques require very high scanning speeds to reduce the processing time to an acceptable level. For macroscopic objects with sub-millimeter resolution, rapid prototyping based on fast photopolymerization of a monomer solution is already industrially established [2].

A method with micrometer resolution has been developed based on a fast silicon dry etching reaction with writing speeds of more than $10 \mathrm{~mm} / \mathrm{s}$ [3].

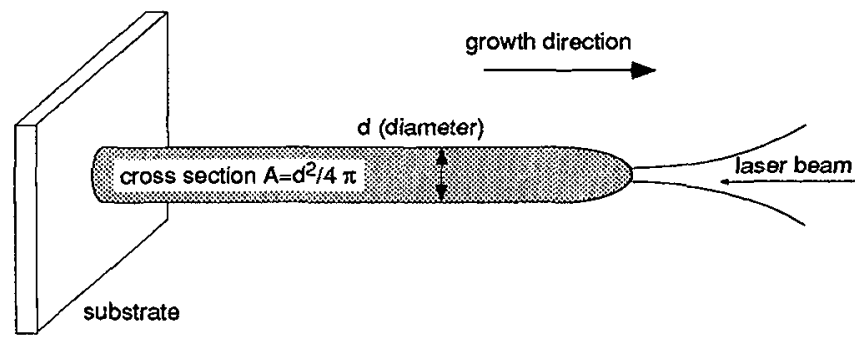

Figure 1: Laser direct writing of rods and fibers. The laser beam is focused onto the tip of the rod and tracked as the rod grows by deposition from the gas phase. 
Conventional two-dimensional laser direct write techniques work by scanning a focused laser beam over the surface of a suitable substrate, thus heating the surface by absorbed laser light. In a deposition experiment, material from the gas phase condensates on the surface at the laser heated sites [4]. If, however, the laser beam is not moved parallel to the surface, but perpendicular, under certain circumstances a thin rod can be drawn into free space (fig. 1). This can be used for fiber production of several materials [5].

The variety of possible materials includes especially nonmetallic ones like carbon $[6,7]$, silicon $[8,9]$ or boron [10]. This can be attributed to the dependence of the thermal conductivity on temperature [11].

\section{EXPERIMENTAL AND RESULTS}

All three-dimensional structures have been built on suitable substrates mounted inside a small reaction chamber on a turnable holder. The chamber has two tubular connections for precursor supply and vacuum system, respectively. It is fixed on a computerized scanning table that can also be manually controlled by a joystick.

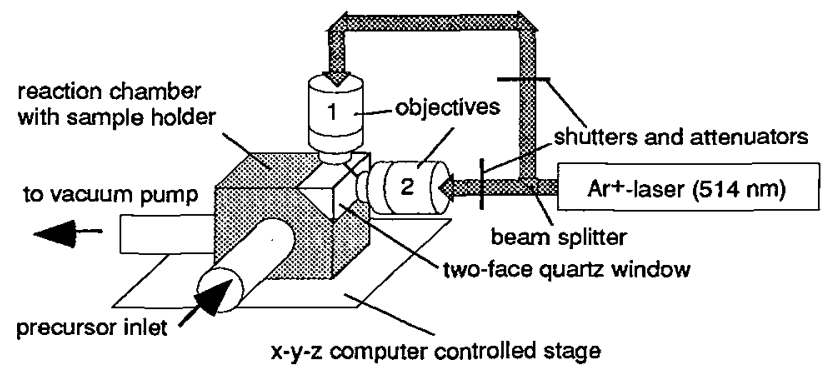

Figure 2: Setup for the deposition of rods and complex laser written structures. The objective lenses generate two overlapping laser spots. Structures are deposited by moving the table under computer control.

Through a two-face quartz window, the structure and the substrate surface can be inspected with an optical microscope. A second objective lens allows observation also under a $90^{\circ}$ angle from the side.

The laser beam, emitted from an argon ion laser working at 488 or $514 \mathrm{~nm}$ (Spectra Physics 2030), is attenuated, split into two separate beams and, after passing two computer-controlled mechanical shutters, focused through the two microscope objective lenses $(8 \mathrm{x}, 0.20 \mathrm{NA})$. The focal spots having a diameter of about $3 \mu \mathrm{m}$ are adjusted to overlap. Both beams or only one can be selected using the shutters. Figure 2 shows a scheme of the setup.

The effective laser power for the experiments was varied between 0.2 and $20 \mathrm{~mW}$.

The aluminum precursor trimethylamine alane (TMAA, $\left.\left(\mathrm{CH}_{3}\right)_{3} \mathrm{NAlH}_{3}\right)$ was pumped slowly through the chamber with a total pressure of about $1.6 \mathrm{mbar}$. For the production of aluminum oxide $\left(\mathrm{Al}_{2} \mathrm{O}_{3}\right)$ rods, oxygen was used as an additional gas with a partial pressure of about $0.2-0.6 \mathrm{mbar}$. The dependence of structure growth on several parameters, such as oxygen partial pressure, has been described elsewhere [11].

Three-dimensional complex structures consisting of rod segments can be produced by moving the substrate under the laser focus. However, only rods parallel or nearly parallel to the incident laser beam can be written directly. To obtain rods in any direction, the substrate has also to be turned during the deposition process [12], or a derived 3D direct write method has to be used.

This method relies on the fact that the absorption length of the laser light in weakly absorbing materials like alumina is high, yielding a rather uniform temperature distribution in the illuminated region. That leads to nondirectional material deposition from the gas phase around the laser spot.

If an additional focused laser beam perpendicular to the first one is adjusted so that the two spots overlap and the laser power is low enough to prevent considerable growth for only one beam, the deposition region is rather well defined by the laser spots. Only here the absorbed energy is sufficient for a temperature rise causing deposition from the gas phase. 
Now, the sample can be moved slowly in any direction with a speed comparable to the growth rate of alumina. This can result in a rod structure with a complex shape, as shown in figure 3.

These structure parts are electrically isolating but can be transferred to conducting by selective laser-CVD coating with aluminum [11].

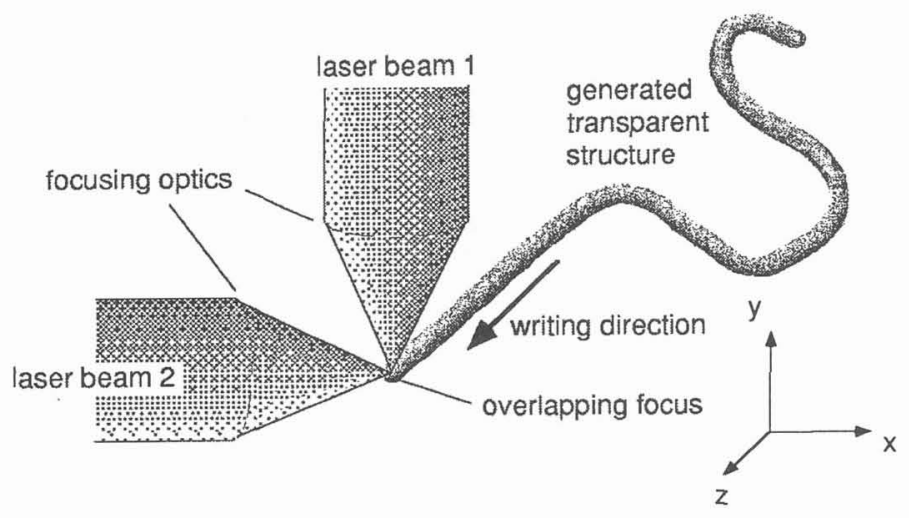

Figure 3: Three dimensional laser direct writing: Complex structures can be generated by moving the overlapping laser spots with respect to the structure, because deposition occurs only in this small region (see text).

Complex structures produced by the method described above are static, since every part is fixed directly or indirectly to the substrate. However, slight bending of structure parts is possible by local laser heating under vacuum. Because the thermal expansion coefficient of aluminum is considerably higher than that of $\mathrm{Al}_{2} \mathrm{O}_{3}$, rods to be used for this purpose have been coated with aluminum. Another aspect is the much higher thermal conductivity of aluminum that results in a uniform temperature distribution.

To get larger moves, lever constructions can be used. In figure 4, a picture of a set of microtweezers is shown that uses this principle.

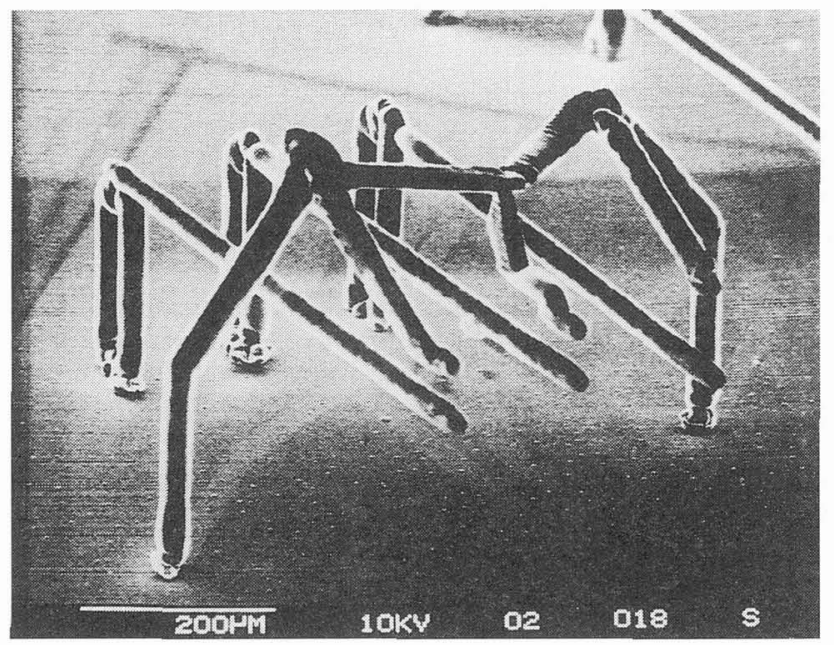

Figure 4: SEM picture of a triple set of microtweezers made by 3D laser direct writing. The tips are bent together by heating one of the holders seen at the left by laser irradiation.

The different thermal expansion of aluminum and alumina can also be used to cut rod connections to the substrate. To achieve this, two parallel vertical aluminum coated rods connected at the top are laser heated alternatively. The thermal strain can lead to disconnection of the rod bases from the substrate. Freely moveable 
structure parts can be manufactured using this method by releasing them from the substrate after their shape has been defined by 3-D laser direct writing.

Using the techniques described above, a simple linear micromotor with a travel of about $100 \mu \mathrm{m}$ has been developed. Its moving part is driven by consecutive heating of different aluminized rods of the fixed structure part. This is shown schematically in figure 5 .

Heating of rod (a) or (c) expands these rods, bending the structure slightly to the right or to the left, respectively. Hence, point $(\mathrm{P})$ is moved to the right or to the left. After switching off the laser beam, the shape of the structure returns to its initial state.

Rod (b) is used for vertical movements. Heating this rod results in a lifting of point $(P)$.

All travels are increased by lever constructions to values of $10-20 \mu \mathrm{m}$ at the lever end.

The principle of the linear movement is presented also in figure 5. By scanning the defocused laser beam (diameter $\sim 50 \mu \mathrm{m}$ ) from the left to the right over the rods (a)-(c), the freely moveable horizontal rod (f) is moved about $5 \mu \mathrm{m}$ to the right and placed back on the holders.

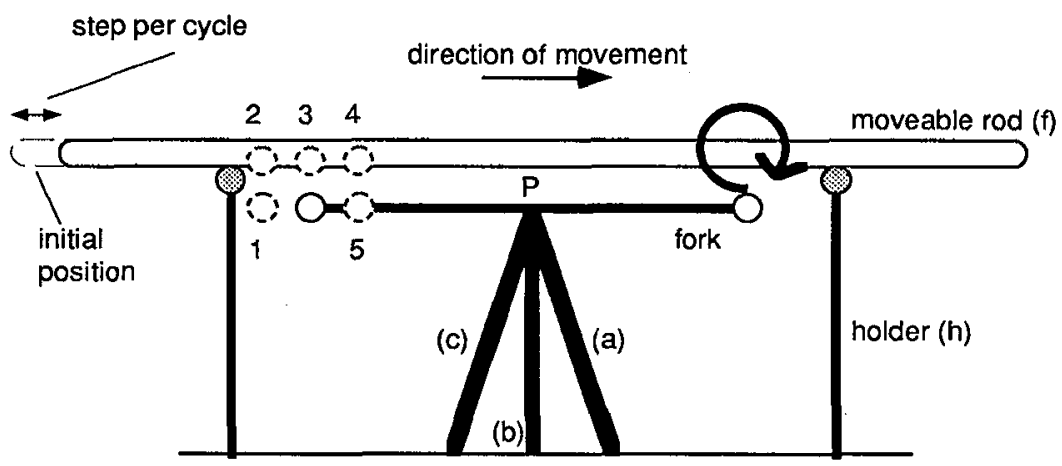

Figure 5: Sketch of the linear micromotor. The levers used for connection between the rods (a)-(c) and the shifting fork are not shown for simplicity. By sequential heating of the rods, the fork can be moved through sequence 1-5 in the arrow direction, as described in the text.

(1) Heating of (a) moves the lever to the left.

(2) Heating of (a) and (b) moves the lever up. Rod (f) is lifted from the holders ( $h$ ) and rests on the lever.

(3) Heating of only (b) results in return to the middle horizontal position.

(4) Heating of (b) and (c) moves the lever further to the right.

(5) Heating of only (c) lowers the lever. Rod (f) is placed back onto the holders (h), however, the position is shifted to the left compared to the initial state.

(6) Stopping of heating (c) restores also the horizontal beginning position of the lever. The motor is now ready for a new cycle. The working principle is similar to the contraction of a muscle via myosin-actin interaction.

In figure 6, a set of snapshots of the movement is shown, starting at the initial position (1) and after 5, 10, 15 , and 20 cycles, respectively.

The direction of movement is determined by the scanning direction of the laser beam. Hence, the rod can be driven either to the left or to the right. 


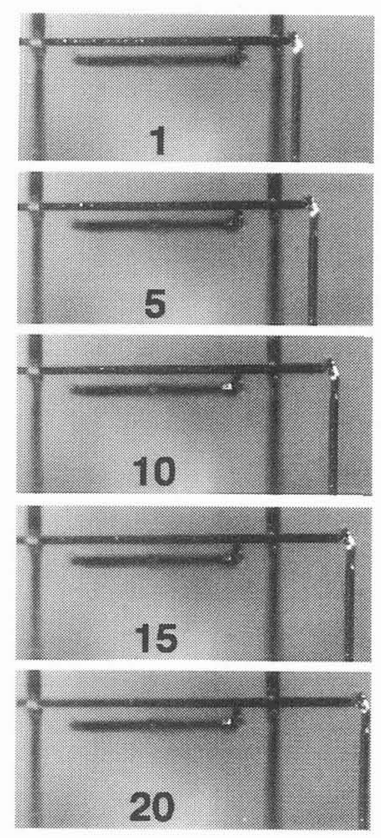

Figure 6: Snapshots of the movement of a linear micromotor after 1,5,10,15 and 20 cyles, respectively. The total travel from (1) to $(20)$ is about $100 \mu \mathrm{m}$, and the rod diameter is between 10 and $15 \mu \mathrm{m}$.

\section{SUMMARY AND OUTLOOK}

In this paper, a new method for the generation of micromechanical devices like microtweezers and micromotors has been presented. This method is based on a three-dimensional laser direct write process. Since the required number of processing steps is very low and no photomasks are used, quick sample processing becomes possible, enabling rapid structure development from first models to final working devices.

\section{Acknowledgements}

The authors would like to thank K. Müller for expert technical assistance. Financial support by BMFT $13 \mathrm{~N} 6159$ is gratefully acknowledged.

\section{References}

[1] O. Lehmann, M. Stuke, Appl. Phys. A 53 (1991) 343

[2] see, for example D. A. Belforte, Laser Focus World, June 1993, p. 126

[3] T. M. Bloomstein, D. J. Ehrlich, Appl. Phys. Lett. 61 (1992) 708

[4] D. Bäuerle, Chemical Processing with lasers (Springer Ser. Mat. Sci. 1, Berlin 1987)

[5 ] F. T. Wallenberger, Science 267 (1995) 1274

[6] G. Leyendecker, D. Bäuerle, P. Geittner, H. Lydtin, Appl. Phys. Lett. 39 (1981) 921

[7] F. T. Wallenberger, P. C. Nordine, Science 260 (1993) 66

[8 ] D. Bäuerle, G. Leyendecker, D. Wagner, E. Bauser, Y. C. Lu, Appl. Phys. A 30 (1983) 147

[9] P. C. Nordine, S. C. de la Veaux, F. T. Wallenberger, Appl. Phys. A 57 (1993) 93

[10 ] F. T. Wallenberger, P. C. Nordine, Mater. Lett. 14 (1992) 198

[11 ] O. Lehmann, M. Stuke, Mater. Lett. 21 (1994) 131

[12] M. Boman, H. Westberg, S. Johannson, J.-A.. Schweitz, Proceedings of IEEE Workshop on Micro Electro Mechanical Systems (Travemünde 1992) p. 162 